\title{
Produção científica sobre adoção por casais homossexuais no contexto brasileiro
}

\author{
Mariana Silva Cecílio \\ Fabio Scorsolini-Comin \\ Universidade Federal do Triângulo Mineiro \\ Manoel Antônio dos Santos \\ Universidade de São Paulo-Ribeirão Preto
}

\begin{abstract}
Resumo
Um dos desafios dos estudos da família contemporânea é a compreensão dos arranjos constituídos por laços socioafetivos, como na adoção, quando os pais ou mães são do mesmo sexo. Este estudo teve por objetivo investigar a produção científica brasileira acerca da homoparentalidade adotiva, entendendo-a como parte dos novos paradigmas relacionados à família e gênero. Realizou-se uma revisão sistemática da literatura científica nacional nas bases LILACS, PePSIC, SciELO e Portal Nacional BVS Brasil em Saúde, de 2000 a 2010. Foram recuperados dez estudos, sendo sete teóricos e três empíricos. Os estudos questionam as descrições tradicionais de família, destacando a necessidade de ampliação dos sentidos de arranjo familiar para além da tradição heteronormativa. Tais reflexões podem abrir espaço para a intervenção crítica de profissionais no contexto da adoção por casais homoafetivos, submetendo a um crivo rigoroso teorias que se mostram insuficientes para dar conta das profundas transformações processadas nas famílias.
\end{abstract}

Palavras-chave: homoparentalidade; adoção; papéis parentais; família.

\begin{abstract}
Scientific production on adoption by gay couples in Brazilian context. One of the challenges of contemporary family studies is to understand the arrangements constituted by socio affective ties, as in adoption, in same sex parents or mothers. This study aimed to investigate the national scientific literature on adoptive homoparenthood, understanding it as part of new paradigms related to the family and gender. A sistematic review was conducted in LILACS, PEPSIC, SciELO and Portal Nacional BVS Brasil em Saúde databases, in the period of 2000 to 2010 . The results evidenced that the studies challenge the traditional descriptions of the family, highlighting the need an expansion of the meanings of family arrangement beyond heteronormative tradition. These considerations may open space for critical intervention of professionals in the context of adoption by homosexual couples, promoting a rigorous examination of theories which are still insufficient to account for the profound changes processed in families.
\end{abstract}

Keywords: homoparenthood; adoption; parental roles; family.

\section{Resumen}

Producción científica sobre la adopción por parejas homosexuales en el contexto brasileño. Uno de los desafíos sobre los estudios de la familia contemporánea es entender el régimen constituido por lazos socioafectivos, como en la adopción, cuando los padres o madres son del mismo sexo. Este estudio tuvo por objetivo investigar la producción científica brasileña sobre la homoparentalidad adoptiva, entendiéndola como parte de los nuevos paradigmas relacionados con la familia y el género. Se realizó una revisión sistemática de la literatura científica nacional sobre las bases LILACS, PePSIC, SciELO y del Portal Nacional BVS Brasil em Saúde, de 2000 a 2010. Se recuperaron diez estudios, siendo siete teóricos y tres empíricos. Los estudios cuestionan las descripciones tradicionales de familia, destacando la necesidad de ampliar el significado de la constitución familiar más allá de la tradición heteronormativa. Estas reflexiones pueden abrir espacio para la intervención crítica de profesionales en el contexto de la adopción por parejas homosexuales, submetiendo a un riguroso escrutinio, teorías que se muestran insuficientes para explicar las profundas transformaciones procesadas en las familias.

Palabras clave: homoparentalidad; adopción; roles parentales; familia. 
A busca dos homossexuais pela constituição da conjugalidade e da parentalidade pode ser compreendida a partir de um panorama histórico que destaca a emergência do modelo individualista moderno, inspirado nos casais de dupla carreira sem filhos das grandes metrópoles, bem como na repercussão da AIDS sobre a comunidade LGBT nas décadas de 1980 e 1990, que teria promovido a conjugalidade como forma de proteção à contaminação. Outros motivos podem ser elencados, até mesmo uma ruptura com o paradigma da liberação sexual na década de 1970 (Grossi, 2003; Heilborn, 1992). A parentalidade constituída por duas pessoas do mesmo sexo tem sido nomeada como homoparentalidade, termo criado na França, no final do século XX. Embora seja um termo criticado justamente por remeter à orientação sexual dos pais, tem sido aceito e utilizado na maior parte dos estudos dedicados a essa temática (Fonseca, 2008; Santos, 2004; Tarnovski, 2002; Uziel, 2007), motivo pelo qual será empregado nesta investigação.

A partir do reconhecimento do estatuto legal das uniões entre pessoas do mesmo sexo em diversas partes do mundo, os primeiros estudos desenvolvidos na área buscavam, notadamente, compreender a implicação da homoparentalidade na criação e no desenvolvimento dos filhos (Barrett \& Tasker, 2001; Beaumatin, Ricaud-Droisy, \& Espiau, 2003; Dortier, 2002; Farias, 2010; Fine, Laterrasse, \& Zaouche-Gaudron, 1998; Langouët, 1998; Mello, 2005a; Solis-Ponton, 2002). Posteriormente, as investigações passaram a se debruçar sobre as alternativas de acesso à parentalidade por parte de homossexuais, como as tecnologias reprodutivas e a adoção (Grossi, 2003; Moris, 2008). No presente estudo, abordaremos especificamente a família constituída por casal homoafetivo que acede à parentalidade por meio da adoção.

Uma premissa que dificulta a adoção por casais homoafetivos é de que a criança sofreria prejuízos em seu desenvolvimento em relação aos processos de identificação e constituição de sua identidade, devido à ausência de referências paterna e materna. Essa premissa é apoiada por boa parte dos estudos internacionais (Dortier, 2002; Fine et al, 1998; Langouët, 1998; Solis-Ponton, 2002), embora não haja qualquer comprovação de que a orientação homossexual possa ser transmitida em famílias compostas por casais homossexuais (Araújo \& Oliveira. 2008; Araújo, Oliveira, Sousa, \& Castanha, 2007; Bailey, Bobrow, Wolfe, \& Mikach, 1995; Costa, 2006; Dias, 2004; Golombok \& Tasker, 1996). Um dos argumentos sustentados é que a maior parte dos homossexuais é proveniente de casais tipicamente heterossexuais. Tais argumentos encontram ressonância na literatura científica (Vecho \& Schneider, 2005).

No Brasil, como a adoção por casais homoafetivos não é regulamentada por lei, muitos homossexuais optam por formalizar o pleito de "guarda única" da criança, configurando-se como um caso de monoparentalidade. Em alguns casos, depois do processo adotivo, a criança passa a ser criada pelo casal homoafetivo. Entretanto, existem casos de abertura legal, como os ocorridos nos municípios de Bagé (RS) e Catanduva (SP), em 2004, em que foi concedida a adoção homoparental legitimada juridicamente (Castro, 2008), em decisões até então inéditas no país. Para que seja deferida a adoção conjunta, é indispensável que os adotantes sejam casados legalmente ou que mantenham união estável, sendo comprovada a estabilidade da família. A extensão aos homossexuais do reconhecimento da união estável pelo Supremo Tribunal Federal em 2011 foi um passo crucial para que se possa, no futuro, regulamentar a prática da adoção por esses casais (Scorsolini-Comin \& Cecílio, 2012), o que ainda não é possível devido à atual Lei ${ }^{0} 12.010$ acerca da adoção, revista recentemente (Brasil, 2009).

A fim de orientar os casais homoafetivos pretendentes à adoção, o Conselho Federal de Psicologia [CFP] (2008) criou uma cartilha que contempla artigos de pesquisadores brasileiros sobre o tema (Mello, 2005b; Uziel, 2007), com o intuito de desmistificar os preconceitos sobre a adoção e apresentar referências que permitam nortear a atuação dos psicólogos. A homoparentalidade adotiva ainda é um tema polêmico, que vem sendo alvo de estudos no campo do Direito, Serviço Social e Psicologia, embora tais pesquisas não tenham repercutido ainda em uma postura de maior aceitação dessa forma de parentalidade (Silva \& Tavares, 2007).

Desse modo, ainda está em pauta a garantia de direitos elementares de cidadania, como a permissão de filiação para aqueles que desejam constituir uma família por laços não consanguíneos, além da promoção de um lar social e afetivo para as crianças afastadas da família biológica. No contexto internacional, Vecho e Schneider (2005) destacaram que a maior parte dos estudos provém dos Estados Unidos, seguido pelo Reino Unido, Bélgica, Dinamarca, França e Canadá, sendo que o Brasil não é mencionado na produção científica dos últimos 30 anos.

A partir desse panorama, este estudo teve por objetivo apresentar uma revisão crítica da literatura científica nacional acerca da homoparentalidade adotiva e investigar os novos paradigmas relacionados aos arranjos familiares e de gênero, principalmente na perspectiva psicossocial desta nova configuração familiar. A meta do estudo é traçar um perfil das publicações brasileiras na área, permitindo compreender de que modo o meio científico, notadamente a Psicologia, tem contribuído para balizar a discussão científica e deflagrar a necessidade de novas produções.

\section{Método}

\section{Tipo de estudo}

Trata-se de uma revisão crítica de literatura que objetiva contribuir para delimitar a produção existente em um determinado contexto (nacional e/ou internacional), permitindo que se apontem lacunas, limites e também possibilidades de investigações que contemplem a temática de interesse de modo mais completo e aprofundado. Desse modo, não basta que apontemos a produção existente e suas características, é preciso lançar ao acervo constituído uma visão crítica acerca do processo de construção do conhecimento na área.

\section{Bases de dados}

Como o objetivo da revisão foi recuperar trabalhos desenvolvidos no contexto nacional, foram consultadas as bases LILACS, PePSIC, SciELO e Portal Nacional BVS 
Brasil em Saúde, sendo, portanto, priorizadas as base de dados latino-americanas, todas engajadas na difusão do conhecimento científico.

\section{Critérios de inclusão e exclusão dos estudos}

Nesta revisão, foram selecionados apenas artigos indexados, visto que estes passam por um processo de avaliação rigorosa de pares. Sendo assim, foram excluídos artigos não indexados, livros, capítulos de livros, resumos publicados em anais de congressos, teses, dissertações, monografias, resenhas e notícias. Foram incluídos trabalhos concernentes ao assunto abordado, sem restrição de idioma. Foram descartados aqueles que não se relacionavam ou não se aproximavam do tema homoparentalidade e adoção. O período selecionado foi de 2000 a 2010, buscando-se priorizar a produção recente acerca do tema. A revisão não se restringiu apenas à seleção de trabalhos produzidos no campo da Psicologia. Optamos por não delimitar a área na qual os artigos foram publicados primando, assim, pelo diálogo inter e multidisciplinar, haja vista que a temática não tem sido objeto de investigação exclusiva de um único campo do saber.

\section{Procedimento}

A etapa de levantamento de artigos ocorreu entre novembro de 2010 e abril de 2011. Foram utilizados os descritores: adoção, homoparentalidade adotiva, homoparentalidade, parentalidade, homossexualidade, homossexualidade e adoção. Há que se destacar que o termo homoparentalidade ainda não faz parte das terminologias em Psicologia e nas Ciências da Saúde, conforme busca no portal da Base Virtual em Saúde. Em um primeiro momento, foi realizada uma leitura minuciosa dos resumos encontrados a partir desses unitermos, excluindo-se os trabalhos que não se enquadravam nos critérios de inclusão elencados. Após uma primeira seleção pelos resumos, os trabalhos selecionados foram recuperados e lidos na íntegra. Posteriormente, em função da maior ou da menor proximidade com o tema, uma nova seleção foi realizada, restringindose a revisão apenas aos artigos diretamente relacionados à homoparentalidade adotiva. Desse modo, foram considerados para discussão apenas os artigos recuperados nessa última etapa da seleção.

Primeiramente, foram selecionados 19 resumos de artigos, de acordo com a temática e os descritores elencados. Posteriormente, segundo os critérios de inclusão/exclusão adotados, nove desses artigos foram descartados por não serem pertinentes ao assunto investigado. Os artigos descartados não se enquadravam na temática por abordarem: avaliação psicossocial e motivação dos pais (heterossexuais) para adoção, movimentos homossexuais, a conjugalidade homossexual e o significado de família para homossexuais. Foram selecionados e recuperados na íntegra 10 artigos. Após uma análise criteriosa, os conteúdos dos artigos foram categorizados em eixos de análise, de modo a facilitar a organização dos dados: caracterização do tipo de estudo, objetivos, método empregado e principais resultados. Dessa forma, foi possível a reflexão dos pontos principais que compõem a temática, e as semelhanças e discordâncias presentes neles.

\section{Resultados}

A Tabela 1 permite visualizar os passos do procedimento de seleção dos artigos e sua recuperação na íntegra, a partir das palavras-chave utilizadas em cada base indexadora. Apresentase o número de artigos encontrados, selecionados e recuperados para análise. A partir da aplicação dos critérios de inclusão/ exclusão e da retirada dos estudos repetidos, foram recuperados 10 artigos.

Tabela 1

Etapas do Procedimento de Seleção de Artigos na Íntegra e Quantidade de Estudos em Cada Fase de Seleção

\begin{tabular}{lccc}
\hline \multicolumn{1}{c}{ Unitermos } & Encontrados & Selecionados & Recuperados \\
\hline Adoção & 10289 & 4 & - \\
Homoparentalidade adotiva & - & - & - \\
Homoparentalidade & 12 & 6 & 4 \\
Parentalidade & 104 & 3 & 2 \\
Homossexualidade & 19397 & 4 & 2 \\
Homossexualidade/Adoção & 98 & 1 & 1 \\
Parentalidade/Homossexualidade & 3 & 1 & 1 \\
Total & 29903 & 19 & 10 \\
\hline
\end{tabular}

A Tabela 2 permite identificar a amostra de artigos recuperados em termos de título, autores, ano de publicação, título do periódico e tipo de estudo.

Conforme mostra a Tabela 2, três artigos são de cunho empírico e sete de caráter teórico. Do ponto de vista da população investigada, os estudos empíricos incluíram: estudantes universitários de Psicologia e de Direito (Araújo et al., 2007), dois casais homoafetivos (Rodriguez \& Paiva, 2009) e uma família recomposta homoparental feminina (Medeiros, 2006). No que se refere ao ano de publicação, o ano de 2006 concentrou o maior número de publicações (cinco). Os demais artigos foram publicados em 2003, 2005, 2007, 2008 e 2009. Três foram publicados em um mesmo periódico: Revista Estudos Feministas; os demais foram publicados nas revistas: Cadernos Pagu, Psicologia Clínica, Ágora, Aletheia, Horizontes Antropológicos, Psicologia \& Sociedade e Vínculo: Revista do 
Tabela 2

Identificação dos Artigos Recuperados Segundo o Título, Autores, Ano, Periódico em que Foram Publicados e Tipo de Estudo

\begin{tabular}{|c|c|c|c|c|c|}
\hline & Título & Autores & Ano & Periódico & $\begin{array}{l}\text { Tipo do } \\
\text { estudo }\end{array}$ \\
\hline 1 & $\begin{array}{l}\text { Gênero e parentesco: famílias gays e lésbicas } \\
\text { no Brasil }\end{array}$ & Grossi & 2003 & Cadernos Pagu & Teórico \\
\hline 2 & $\begin{array}{l}\text { Homoparentalidade: uma entre outras formas } \\
\text { de ser família }\end{array}$ & Passos & 2005 & Psicologia Clínica & Teórico \\
\hline 3 & $\begin{array}{l}\text { Reflexões acerca das novas formas de } \\
\text { parentalidade e suas possíveis vicissitudes } \\
\text { culturais e subjetivas }\end{array}$ & Amazonas, Braga & 2006 & $\begin{array}{l}\text { Ágora: Estudos em Teoria } \\
\text { Psicanalítica }\end{array}$ & Teórico \\
\hline 4 & $\begin{array}{l}\text { Adoção por homossexuais: uma nova } \\
\text { configuração familiar sob os olhares da } \\
\text { Psicologia e do Direito }\end{array}$ & Futino, Martins & 2006 & Aletheia & Teórico \\
\hline 5 & $\begin{array}{l}\text { "Uma família de mulheres": ensaio etnográfico } \\
\text { sobre homoparentalidade na periferia de São } \\
\text { Paulo }\end{array}$ & Medeiros & 2006 & Revista Estudos Feministas & Empírico \\
\hline 6 & $\begin{array}{l}\text { A parentalidade homossexual: uma exposição } \\
\text { do debate psicanalítico no cenário francês atual }\end{array}$ & Perelson & 2006 & Revista Estudos Feministas & Teórico \\
\hline 7 & $\begin{array}{l}\text { Parentalidades "impensáveis": pais/mães } \\
\text { homossexuais, travestis e transexuais }\end{array}$ & Zambrano & 2006 & Horizontes Antropológicos & Teórico \\
\hline 8 & $\begin{array}{l}\text { Adoção de crianças por casais homoafetivos: } \\
\text { um estudo comparativo entre universitários de } \\
\text { Direito e de Psicologia }\end{array}$ & $\begin{array}{l}\text { Araújo, Oliveira, } \\
\text { Sousa, Castanha }\end{array}$ & 2007 & Psicologia \& Sociedade & Empírico \\
\hline 9 & $\begin{array}{l}\text { Homoparentalidade: novas luzes sobre o } \\
\text { parentesco }\end{array}$ & Fonseca & 2008 & Revista Estudos Feministas & Teórico \\
\hline 10 & $\begin{array}{l}\text { Um estudo sobre o exercício da parentalidade } \\
\text { em contexto homoparental }\end{array}$ & Rodriguez, Paiva & 2009 & $\begin{array}{l}\text { Vínculo: Revista do } \\
\text { NESME }\end{array}$ & Empírico \\
\hline
\end{tabular}

NESME.

\section{Objetivos dos estudos}

Em relação aos objetivos dos artigos recuperados, Grossi (2003) tece reflexões em torno das configurações familiares, incorporando pesquisas brasileiras desenvolvidas nos últimos anos, que se interessam, sobretudo, por como essas constelações têm sido abordadas na mídia e angariado maior visibilidade. Examinando teoricamente o exercício da homoparentalidade, Passos (2005) discute as significativas mudanças ocorridas no âmbito das relações conjugais e parentais. Já o artigo de Rodriguez e Paiva (2009) apresenta o resultado de uma pesquisa realizada com dois casais, focalizando as especificidades do relacionamento homoparental, visando a compreender o olhar dos pais quanto a seus papéis nesse tipo de arranjo familiar.

Discutir o impacto cultural e subjetivo, bem como a influência do modelo tradicional da família na construção de parentalidades que até há pouco tempo eram consideradas impensáveis, é o objetivo dos estudos de Amazonas e Braga (2006) e de Zambrano (2006). O primeiro levanta a questão das mudanças ocorridas nos papéis parentais e de gênero, bem como as repercussões das novas possibilidades de controle sobre a procriação engendradas pelas biotecnologias. O segundo estudo enfatiza o desafio de desconstruir antigas certezas, cristalizadas nos arranjos familiares tradicionais, de modo a favorecer a legitimação e o enfrentamento das implicações suscitadas pelas novas demanda sociais.
Os estudos de Futino e Martins (2006) e de Araújo et al. (2007) privilegiam uma perspectiva comparativa, a partir dos olhares da Psicologia e do Direito. O artigo de Futino e Martins (2006) teve por objetivo discutir as possibilidades de adoções por homossexuais no país. Araújo et al. (2007) buscaram analisar e comparar as representações sociais de estudantes dos cursos de graduação em Psicologia e Direito acerca da adoção homoafetiva. O estudo de Medeiros (2006) teve por objetivo refletir sobre uma família recomposta homoparental feminina da periferia de São Paulo, elegendo como eixos da discussão a conjugalidade e o relacionamento com as filhas, com a família extensa e com o ex-marido.

Para finalizar, o estudo de Perelson (2006) buscou desmontar os argumentos contrários e indicar a legitimidade da argumentação favorável à filiação homossexual. Já o estudo de Fonseca (2008) remontou a outros trabalhos que investigaram a noção de "família que escolhemos", focando a recriação de ideologias de parentesco por casais homossexuais e questionamentos em relação à ideia de escolha individual pela adoção.

\section{Estratégia metodológica e instrumentos utilizados}

$\mathrm{Na}$ presente revisão de literatura predominaram estudos teóricos. Foram identificados três estudos empíricos (Araújo et al., 2007; Medeiros, 2006; Zambrano, 2006). O estudo de Medeiros (2006) utilizou como estratégia metodológica o estudo de caso. Foram recuperadas entrevistas baseadas na história de 
vida dos sujeitos, obtidas em ocasião anterior, e aprofundou-se a coleta de dados e o acompanhamento de um desses sujeitos, uma mulher lésbica da periferia da cidade de São Paulo, articulando-se atributos antes não levantados e explorados devido à delimitação do recorte.

No estudo de Araújo et al. (2007) foi utilizada abordagem mista: quantitativa e qualitativa. A primeira para identificação dos dados sociodemográficos, definindo o perfil dos participantes, que eram estudantes de Direito e Psicologia, do final do curso de graduação. O componente qualitativo foi contemplado por meio de uma entrevista baseada em uma única pergunta aberta.

Utilizando-se do método clínico-qualitativo, o estudo de Rodriguez e Paiva (2009) coletou dados por meio de entrevista semidirigida e do procedimento de Desenhos de Família com Estórias. O objetivo foi investigar o exercício da homoparentalidade. Participaram dois casais homossexuais, um masculino e outro feminino.

Em linhas gerais, os artigos teóricos basearam-se em teorias existentes, com predomínio da psicanálise (Amazonas \& Braga, 2006; Passos, 2005; Perelson, 2006) ou a teoria do apego (Futino \& Martins, 2006), aplicadas ao contexto da homoparentalidade. Os estudos reportaram resultados de pesquisas brasileiras e internacionais (principalmente no contexto francês) publicadas na área. Foram realizadas revisões narrativas sobre o tema e discutidos casos de domínio público veiculados na mídia (Grossi, 2003). Os artigos também recuperaram a legislação vigente no campo da adoção, analisada na interface com a Psicologia, Direito e Ciências Sociais (Fonseca, 2008; Futino \& Martins, 2006; Zambrano, 2006).

\section{Discussão}

\section{Ampliação do conceito de família}

Considerando a atual reconstrução de paradigmas, a fim de incluir socialmente a família homoafetiva, Grossi (2003) aborda que as famílias gays e lésbicas vêm cada vez mais buscando a legitimação da parceria civil, conforme tem repercutido na mídia, devido à forte implicação política e religiosa envolvida. Há uma preocupação com as possíveis explicações que são oferecidas para a singularidade do desejo que permeia essa conjugalidade e como se deu a construção da identidade homossexual, bem como as diferentes e possíveis formas de filiação no Brasil. O entrave jurídico à adoção homoafetiva e a possibilidade de "guarda única" (monoparentalidade) vêm sendo seguidos de aberturas para outras possibilidades em diferentes regiões do país, o que também é discutido por Castro (2008).

Em termos da experiência da parentalidade relacionada à adoção, Grossi (2003) também aborda a necessidade de lidar com o luto derivado da não concepção natural por parte dos pais. Os resultados permitem afirmar que essas famílias deixaram de ser invisíveis nos estudos dedicados à família e às relações de parentesco nas sociedades contemporâneas. Podemos perceber as dificuldades presentes na conquista da plena cidadania e na falta de reconhecimento social das uniões homoafetivas como um contexto familiar possível e não tradicional.

Em relação a esse aspecto, Ruas et al. (2009) exploraram a questão dos preconceitos que envolvem a adoção, sobretudo a adoção por pares homossexuais. Segundo esses autores, ao se proibir um casal homossexual de adotar, está se abandonando mais uma vez a criança ou o adolescente que, normalmente, permanece institucionalizado. Esse preconceito, longe de promover um ambiente seguro emocionalmente para a criança, acaba por reforçar a sua exclusão de uma sociedade na qual circulam concepções tradicionais e um tanto quanto engessadas de família.

Rodriguez e Paiva (2009) também reconhecem a não adequação de um único modelo para explicar os diversos arranjos familiares existentes. Para as autoras, a noção de família é uma entidade dinâmica, e seu exercício homoafetivo deve ser abarcado nas novas descrições de família, como também evocado no estudo de Perelson (2006). Retomando as considerações de Winnicott (1993), não é a orientação sexual dos pais que interferirá no desenvolvimento psíquico da criança, e sim a qualidade do vínculo, consanguíneo ou não, estabelecido com seus cuidadores. A partir dessa consideração, Rodriguez e Paiva (2009) alertam para a necessidade de trabalhar junto a essas famílias no sentido de promover ambientes facilitadores do desenvolvimento, nos quais pais e filhos possam se vincular, trocar experiências, reconhecer e prover suas necessidades básicas a partir do contato com o outro e sua subjetividade. A necessidade do ambiente facilitador não seria exclusiva desses arranjos, mas de todo sistema familiar, composto ou não por casais homossexuais.

As dificuldades legais para o reconhecimento dessas famílias, bem como a discriminação e o preconceito que envolvem não apenas o casal homoafetivo, como também a criança adotada, acabam por repercutir no modo como essas famílias têm se estruturado e se reconhecido em termos de sua identidade. Essa identidade não passaria apenas pelo reconhecimento do pacto conjugal, mas pela aceitação de um arranjo familiar não convencional, que vem fomentando uma revisão das próprias noções consagradas de família e parentesco (Grossi, 2003). O que seria família no contexto contemporâneo? O que definiria as funções sociais de pai e mãe nos múltiplos arranjos familiares da atualidade? Os artigos analisados (Fonseca, 2008; Futino \& Martins, 2006; Medeiros, 2006; Perelson, 2006; Zambrano, 2006) preconizam a necessidade não apenas de revisão dessas definições, como de ruptura com noções que visam ao estabelecimento de padrões e normativas que não mais abarcam a diversidade (CFP, 2011), não apenas no contexto homoafetivo, como também de famílias monoparentais e dos recasamentos, por exemplo. Desse modo, a redefinição do conceito tradicional de família, em razão da necessidade de ampliá-lo no cenário contemporâneo, é um argumento recorrente em todas as produções recuperadas, o que denota uma preocupação da literatura científica em apresentar posicionamentos menos herméticos e mais condizentes com as transformações da sociedade e os contornos atuais da conjugalidade e da parentalidade.

\section{A desconstrução de uma verdade única sobre a fami- lia homoafetiva}

Conforme criticado nos estudos recuperados (Amazonas 
\& Braga, 2006; Grossi, 2003; Rodriguez \& Paiva, 2009), a insuficiência ou ausência de uma definição notadamente ampla, diversa e, ao mesmo tempo, complexa sobre a família, tem gerado práticas uniformizantes que, geralmente, elegem um modelo heteronormativo, nuclear e tradicional como mais "adequado" ou como um padrão não apenas a ser seguido, mas também ao qual arranjos familiares considerados alternativos devem ser comparados. A construção do que vem a ser a homoparentalidade, desse modo, dar-se-ia a partir do modelo de parentalidade experienciado por pessoas/casais tipicamente heterossexuais. Assim, a homoparentalidade poderia ser compreendida como um construto diferente do conceito de parentalidade, recaindo sobre o termo o peso da orientação sexual da pessoa que se torna pai/ mãe. Embora haja um consenso de que a nomenclatura utilizada não corresponde ao ideal, ela tem sido empregada de modo a demarcar a produção científica sobre o tema, conferindo-lhe maior coesão. No entanto, é preciso atentar para a necessidade de revisão dessas nomenclaturas por parte dos pesquisadores da área (Uziel, 2007).

Ao discutir a adoção por casais homossexuais, Passos (2005) elenca três aspectos necessários para a compreensão das novas configurações familiares: (a) o contexto mais amplo das relações sociopolíticas que envolvem a questão; (b) a observação de uma ética relacional que dê conta das transformações que ocorrem nos pequenos grupos regidos pelas redes de afeto; (c) a compreensão de que essa ética relacional possa assegurar as especificidades de cada contexto, evitando, em gerações vindouras, posicionamentos preconceituosos e que excluam os cidadãos de seus direitos. As novas formas de ser família, ainda de acordo com Passos (2005), devem ser compreendidas a partir de uma perspectiva ética que considere as demandas afetivas dos sujeitos envolvidos.

Perelson (2006) ressalta que as novas formas de família são decorrentes das práticas sociais desenvolvidas nas famílias - monoparentais, multiparentais e homoparentais, e das emergentes práticas médicas quanto à reprodução, resultantes dos recursos biotecnológicos. Em seu estudo, a referida autora retrata o cenário do efervescente debate psicanalítico na França. Psicanalistas como Joël Dor, Pierre Legendre, Michel Tort, Geneviève Delaisi de Parseval e Sabine Prokhoris são evocados para discutir sobre as reivindicações ao direito do exercício de formas inéditas de paternidade e maternidade. Para tanto, é trazido como pano de fundo o impacto moral e social causado pela liberação na França, em 1999, do "Pacto Civil de Solidariedade" (PACS), que não incluía o direito à filiação por parte do casal. A partir das discussões fomentadas pelo PACS, Perelson (2006) pontua que alguns psicanalistas contemporâneos estão começando a refletir sobre a homossexualidade e, consequentemente, sobre a adoção por casais homoafetivos, com uma conotação menos patologizante e negativa. Nessa direção, Dor levanta a questão de função paterna e as posições identificatórias frente à diferença anatômica entre os sexos. Legendre faz articulações entre o jurídico e o psíquico como elementos fundamentais para a estruturação da identidade da criança. Tort critica a teoria de Legendre e, junto a Prokhoris e Parseval, responde criticamente aos discursos resistentes à conjugalidade e filiação homossexual.
A visão da psicanálise também é privilegiada no estudo de Amazonas e Braga (2006). As autoras afirmam que, apesar de essa abordagem oferecer um rico aporte para os estudos sobre a homoparentalidade, ela não pode ser incensada como uma espécie de guardiã de uma ordem simbólica supostamente única. Identificar as explicações oferecidas pela psicanálise como uma resposta única e definitiva constitui um risco ideológico, que defenderia a existência de uma única verdade acerca das condições perfeitas para um desenvolvimento psíquico considerado normal. O modelo tradicional de família oferecido por leituras mais ortodoxas da psicanálise pode ocasionar equívocos no modo de compreender o bem-estar psíquico dos familiares e a subjetivação das crianças.

A partir desse impasse, também pontuado por Amazonas e Braga (2006), Perelson (2006) pondera que os posicionamentos atuais na psicanálise francesa indicam que não apenas a homossexualidade, mas também a heterossexualidade, devem ultrapassar a tendência a localizar as causas de certos transtornos apenas na diferença entre os sexos. Tal consideração acaba por contribuir, inclusive, no modo como as teorias psicológicas são incorporadas e transmitidas na universidade, como discorreremos a seguir.

\section{Adoção por casais homossexuais: Um campo de disputas}

A preocupação com o modo como essas questões contemporâneas são desenvolvidas e transmitidas no ensino superior podem ser visualizadas a partir dos resultados obtidos no estudo de Araújo et al. (2007). Os achados indicaram que os posicionamentos de universitários de Direito e de Psicologia são contrários à adoção por casais homossexuais, alegando possíveis consequências nocivas em relação à criação e ao desenvolvimento dos filhos, ancorados em um discurso de proteção da criança em relação aos preconceitos da sociedade. Os autores afirmam que esses estudantes reconhecem os modelos monoparentais como passíveis de serem adotantes legais, o que não ocorre quando são questionados acerca dos modelos homoparentais, uma vez que estes seriam carentes do referencial de um dos sexos.

Há que se considerar que esse preconceito também é revelado nessa aparente proteção e é sob o seu manto que eles justificam a oposição a essa modalidade de parentalidade. Há que se considerar que tais repercussões ou consequências não estão amparadas em pesquisas conduzidas com filhos de casais homossexuais, tanto no Brasil como no contexto internacional (Vecho \& Schneider, 2005). Apesar de não aprovarem a adoção, os estudantes universitários compreendem que esta é uma ação inclusiva e que pode contribuir para a construção da cidadania desses casais. Esse paradoxo também foi destacado no estudo de Tavares, Souza, Ferreira e Bomtempo (2010), no campo do Direito. Em termos das reflexões da sociedade contemporânea em torno dessas temáticas, há que se possibilitar um debate amplo na comunidade, inclusive nas universidades (Araújo et al., 2007), a fim de que os profissionais façam um exercício de desconstruir modelos e analisar em que medida suas decisões são amparadas nos mecanismos que efetivamente visam a assegurar a democracia e o bem-estar de todos. Como enfatizado por 
Rodriguez e Paiva (2009, p. 25), no que se refere à formação do psicólogo, é necessário encorajar "a reflexão acerca do que necessitam as famílias homoparentais e como a Psicologia pode auxiliar, tanto com o olhar reflexivo como com posturas clínicas mais flexíveis e livres de pré-conceitos acerca das diferentes manifestações da instituição família".

É com vistas a assegurar o direito de todo e qualquer cidadão constituir uma família e ser protegido por ela, notadamente no caso das crianças e adolescentes, que Futino e Martins (2006) destacam que o processo de adoção no Brasil é cercado de ritos burocráticos que visam garantir o bem-estar do adotando no lar substitutivo. No entanto, o excesso de burocracia acaba afastando candidatos à adoção. No caso dos casais homoafetivos, há dificuldades adicionais. O processo é obstaculizado desde o início, a partir de impedimentos de ordem moral, tornando complexa a tarefa de inserir uma criança ou adolescente em um lar constituído por um casal homoafetivo. Na área do direito das famílias (Tavares et al., 2010), tem-se discutido sobremaneira o reconhecimento de arranjos familiares que se afastam do modelo tradicional, mas que são abarcados pela cláusula aberta das entidades familiares instituída na Constituição Federal de 1988. Aponta-se para a necessidade de que tais questões sejam debatidas para além de juízos morais e religiosos incompatíveis, tanto com a nova ordem jurídica vigente quanto com os novos paradigmas de família.

Diante da inexistência formal de veto legal, como apresentam Futino e Martins (2006), os aspectos morais e educacionais da criação das crianças são preponderantes para a argumentação contrária à adoção, do que os juízes consideram um desenvolvimento psicológico saudável ou adequado. Essas decisões desconsideram os trabalhos conduzidos a esse respeito, notadamente no campo da Psicologia, que comprovam que não há uma transmissão da homossexualidade a partir do parentesco (homo ou heterossexual), assim como o mesmo não ocorre no caso da heterossexualidade. As referidas autoras também denunciam que a formação desses juízes nem sempre possibilita uma discussão democrática e isenta de um viés moral sobre a questão, o que acaba tendo como consequência posturas unilaterais e que não favorecem justamente aquilo que se gostaria de efetivar: que crianças e adolescentes possam ter acesso a um ambiente familiar seguro e afetuoso. Ou, nas palavras das próprias autoras, "se o fundamental é atender às necessidades da criança e sendo o adotante cumpridor de seus deveres, sua orientação sexual não pode ser utilizada como condição de veto" (p. 157).

No estudo de Zambrano (2006) são mencionadas famílias e suas vivências nos papéis de gênero, sendo o fator da diferença dos sexos que perpassa todos os questionamentos e decisões sobre parentalidade. Em outras palavras, a questão da identificação da criança com seu genitor e a sua genitora. Portanto, o resultado é desafiador: destituir antigas certezas para fazer vigorar novos laços afetivos legítimos. As parentalidades não tradicionais se tornam impensáveis, principalmente frente à condenação generalizada da homossexualidade pelos preceitos religiosos, que constitui outro entrave à adoção por casais do mesmo sexo, como sugere Mattar (2008). Essas neoparentalidades são pensadas no estudo de Zambrano (2006) por meio de uma análise das relações entre três domínios: da Antropologia, da Psicanálise e do Direito.

Apesar das recentes mudanças ocorridas em nossa sociedade, que têm tornado mais visíveis as questões caras à população LGBT, as famílias compostas por casais homossexuais parecem ainda estar à margem do conceito de família empregado por alguns operadores do Direito (Araújo et al., 2007; Futino \& Martins, 2006; Zambrano, 2006). Isso pode ser ilustrado pelo fato de que, antes da decisão histórica do Supremo Tribunal Federal em 2011, alguns juristas reconheciam a união homossexual como entidade familiar, e outros não. Mesmo com o reconhecimento da igualdade de direito no que concerne às uniões estáveis, alguns embates já têm sido relatados pela mídia, em função de interpretações que visam a uniformizar os conceitos de família e parentalidade.

\section{Um convite ao diálogo entre teoria e prática}

Observamos, a partir da análise desse corpo de literatura, um predomínio de estudos teóricos a respeito do tema. Essas pesquisas cumprem uma função relevante por possibilitarem um diálogo entre diferentes abordagens dentro de um mesmo campo do conhecimento e também entre diferentes disciplinas da área de ciências humanas e sociais. Tendo a experiência como disparadora de reflexões sobre a temática da homoparentalidade adotiva, Medeiros (2006) entrevistou uma mulher assumidamente homossexual. Nessa pesquisa, procurou-se articular outros atributos etnográficos concomitantemente ao histórico de vida referente à sua orientação sexual. Nesse contexto, um aspecto a ser ressaltado é a forma como assume sua homossexualidade a partir de seu engajamento político e, portanto, público. Relatos de situações homofóbicas de agressão, sobretudo devido à imagem da tríade ("ser lésbica", "ser lésbica de periferia", "vinculação ao movimento lésbico"), a escolha de autoafirmação em se assumir e a cobrança de educação redobrada às filhas são reflexões empreendidas no percurso da pesquisa. De modo geral, outros estudos recuperados na revisão (Passos, 2005; Perelson, 2006; Rodriguez \& Paiva, 2009) também destacam a ideia do papel parental - do ser pai e do ser mãe, como atributo vinculado ao exemplo dos pais (ligado aos modelos tradicionais de família), à cobrança, à moralidade e à responsabilidade.

Problematizando a recriação de ideologias de parentesco no cerne da família homoafetiva, Fonseca (2008) menciona a década de 1980 como época em que muitos jovens estavam "saindo do armário", anunciando à família sua orientação sexual. A autora discute a banalidade da adoção por casais homoafetivos dos Estados Unidos, relatando o fato que se tornou público que uma mulher havia adotado sua própria companheira para que esta pudesse ter direitos "legais"; tempos depois o casal se separou, dando início a uma incessante luta pela disputa dos bens. Outras maneiras de vivenciar a homoparentalidade, como as possibilitadas pelas tecnologias reprodutivas, em que duas mães podem ser classificadas como "mães biológicas", e a questão de "direitos humanos" serem confundidos com "direitos do consumidor" na escolha pela criança perfeita, são mencionadas por Fonseca (2008) e por Amazonas e Braga (2006). Independentemente do fato de o filho ser compreendido, em alguns casos, como um objeto de inclusão social, deve-se ponderar que o direito da criança ter um lar e uma família, 
assim como de qualquer cidadão poder constituir a sua própria família independentemente de sua orientação sexual, são questões emergentes e que ainda estão longe de receber uma resposta conclusiva. O próprio diálogo inter e multidisciplinar, valorizado nos estudos de Araujo et al. (2007) e Zambrano (2006), aponta para diferentes possibilidades de atuação no que se refere à garantia do direito do exercício da parentalidade. Assim, novas contribuições, experiências e saberes derivados de outras investigações são importantes para aquecer o debate.

Majoritariamente, os estudos aqui elencados concebem a diferenciação da configuração familiar homoparental em relação ao modelo tradicional heteronormativo pelo vértice do preconceito sofrido, da falta de apoio e de aceitação social (Medeiros, 2006; Rodriguez \& Paiva, 2009). Porém, alguns abordam a adoção homoafetiva em uma perspectiva francamente negativa, como tentativa de se inserir na sociedade e tornar-se visível a partir do "objeto de consumo: filho" (Amazonas \& Braga, 2006). Defende-se, em geral, a tese de que, independentemente da configuração familiar, o fundamental é assegurar que as crianças sejam cuidadas, desejadas e que possam garantir seu direito de terem um lar, uma vida digna e um futuro, assim como se deve preservar que os casais homossexuais possam ser respeitados e acolhidos em seus desejos de parentalidade.

\section{Considerações finais}

Em termos gerais, a presente revisão demonstrou como o exercício da homoparentalidade é concebido na contemporaneidade, a partir dos estudos publicados no cenário nacional. Vimos que o olhar com que se capta esse objeto ainda é permeado por controvérsias, que o fixam como algo que avilta práticas e saberes ético-morais, religiosos, psicológicos, sociais e jurídicos. Percebeu-se que a adoção por casais homoafetivos ainda é muito estigmatizada e alvo de preconceitos, o que deve ser repensado de forma crescente, nos próximos anos, em função de mudanças significativas na sociedade brasileira, como o reconhecimento da união estável entre pessoas do mesmo sexo.

Os estudos mencionam os entraves impostos à busca pela legitimização da adoção por casais homossexuais, entre eles o pressuposto de que os filhos adotivos sofreriam prejuízos na construção de suas identidades, ocasionando possíveis desvios de personalidade pela falta de referência do gênero oposto, sem contar as discriminações e preconceitos a qual eles estariam expostos. Destaca-se que tais considerações vêm sendo combatidas por Barrett e Tasker, (2001) e Beaumatin et al. (2003), que buscam desconstruir o mito de que pais/mães homossexuais influenciariam a orientação homoafetiva dos filhos, como visto no contexto heterossexual, haja vista que grande parte dos homossexuais são filhos de pais heterossexuais (Farias, 2010).

Em cada categorização elaborada a partir da configuração familiar tradicional, permanece implícita a hegemonia deste arranjo de caráter heteronormativo, que reproduz um "modelo" que visa assegurar a ordem e a domesticação dos sentimentos e a sua perpetuação ao longo do tempo. Segundo algumas pesquisas (Diniz \& Salomão, 2010; Fonseca, 2008; Santos, 2004; Uziel, 2007), em comparação com a constituição familiar considerada mais conservadora, a família homoafetiva parece ser mais flexível em termos dos papéis assumidos pelos seus membros, o que deve ser elucidado por um número maior de estudos na área. Entretanto, sofre devido ao não reconhecimento social e também legal, uma vez que as decisões judiciais em favor do reconhecimento da união estável entre pessoas do mesmo sexo ainda estão sendo absorvidas pela sociedade, ou seja, não se encontram estabelecidas e amplamente respeitadas. Essa consideração torna-se ainda mais válida quando se traz à baila a adoção por casais homoafetivos ou a educação de crianças no contexto desses novos arranjos familiares.

A repercussão contemporânea da temática incita diferentes reflexões, fomentando movimentos da sociedade civil em torno do reconhecimento dessas famílias alicerçadas em laços de um amor que agora ousa dizer o seu nome, o que deveria ocupar de maneira mais sistemática os pesquisadores do contexto brasileiro. As publicações na área devem avançar nos próximos anos, tanto em função da efervescência dessas discussões em diferentes mídias quanto pela necessidade dos saberes $p s i$ posicionarem-se em relação a aspectos sensíveis envolvidos na temática. Esse interesse vem despertando a atenção de grupos de pesquisa de todo o país e de organizações como o Conselho Federal de Psicologia (2008; 2011). Os padrões familiares se transformam ao longo do tempo, exigindo que as pesquisas não apenas relatem as mudanças, mas possam lançar olhares não preconceituosos à questão, desmistificando visões essencialistas e desconstruindo ideias prontas, que facilmente se naturalizam em clichês utilizados nas formas de se conceber a família, a filiação e o parentesco.

As publicações ressaltaram as especificidades das famílias homoafetivas em termos do seu processo de reconhecimento legal e social. Tais estudos ainda são escassos, o que reflete o fato de que apenas recentemente a temática homoafetiva tenha se tornado um assunto "visível" nas ciências humanas. Outro limite encontrado refere-se à própria questão adotiva na homoparentalidade, haja vista que, com a tecnologia reprodutiva em vigor, muitos casais têm recorrido a técnicas de fecundação como alternativa de acesso à homoparentalidade. Estudos empíricos são necessários para iluminar essa questão.

A partir da revisão sistemática empreendida na literatura científica nacional, esperamos fornecer subsídios para estudos subsequentes na área, a fim de favorecer reflexões sobre o exercício dos papéis parentais por casais homoafetivos e, ao mesmo tempo, ampliar os sentidos sobre as novas configurações familiares na contemporaneidade. Acreditamos que tais reflexões podem abrir espaço para a intervenção de profissionais, sobretudo da saúde e juristas, que se deparam com a problemática, contribuindo para a sistematização da assistência nesse contexto. No que concerne particularmente à Psicologia, e inspirados nas problematizações de Passos (2005), devemos desenvolver um enfrentamento rigoroso das teorias, que são "insuficientes para dar conta das profundas transformações processadas nas famílias, sobretudo em seus enredamentos afetivos" (p. 40). Por fim, retomamos o questionamento trazido por Araújo et al. (2007): como será pautado o compromisso social e ético dos profissionais frente a essa problemática, que envolve elementos não apenas psicológicos, mas sociais, culturais, políticos e 
econômicos? Compreendemos que as respostas podem e devem ser oferecidas por novas pesquisas, que possam fazer avançar o conhecimento na área.

\section{Referências}

Amazonas, M. C. L. A., \& Braga, M. G. R. (2006). Reflexões acerca das novas formas de parentalidade e suas possíveis vicissitudes culturais e subjetivas. Ágora: Estudos em Teoria Psicanalítica, 9(2), 177-191.

Araújo, L. F., \& Oliveira, J. S. C. (2008). A adoção de crianças no contexto da homoparentalidade. Arquivos Brasileiros de Psicologia, 60(3), 40-51.

Araújo, L. F., Oliveira, J. S. C., Sousa, V. C., \& Castanha, A. R. (2007). Adoção de crianças por casais homoafetivos: Um estudo comparativo entre universitários de Direito e de Psicologia. Psicologia \& Sociedade, 19(2), 95-102.

Bailey, J. M., Bobrow, D., Wolfe, M., \& Mikach, S. (1995). Sexual orientation of adult son of gays father. Developmental Psychology, 35(1), 124-129.

Barrett, H., \& Tasker, F. (2001). Growing up with a gay parent: Views of 101 gay fathers on their sons' and daughters' experiences. Educational and Child Psychology, 18(1), 62-77.

Beaumatin, A., Ricaud-Droisy, H., \& Espiau, G. (2003). Approche psychologique de l'exercice de la parentalité chez les couples homosexuels. Pratiques Psychologiques, 2, 45-54.

Lei n. 12.010, de 3 de agosto de 2009 (1996, 3 de agosto). Dispõe sobre adoção. Recuperado de http://www.planalto.gov.br/ccivil_03/_ato2007-2010/2009/ lei/112010.htm

Castro, M. C. A. (2008). A adoção em famílias homoafetivas. In Conselho Federal de Psicologia, Adoção: Um direito de todos e todas (pp. 23-26). Brasília: Autor.

Conselho Federal de Psicologia (2008). Adoção: Um direito de todos e todas. Brasília: Autor.

Conselho Federal de Psicologia (2011). Psicologia e diversidade sexual: Desafios para uma sociedade de direitos. Brasília: Autor.

Dias, M. B. (2004). Conversando sobre homoafetividade. Porto Alegre: Livraria do Advogado.

Diniz, P. K. C., \& Salomão, N. M. R. (2010). Metas de socialização e estratégias de ação paternas e maternas. Paideia, 20(46), 145-154.

Dortier, J. F. (2002). Families: Permanences et metamorphoses. Paris: Sciences Humaines Éditions.

Farias, M. O. (2010). Mitos atribuídos às pessoas homossexuais e o preconceito em relação à conjugalidade homossexual e a homoparentalidade. Revista de Psicologia da UNESP, 9(1), 99-109.

Fine, A., Laterrasse, C., \& Zaouche-Gaudron, C. (1998). À chacun sa famille. Toulouse: Éditions Universitaires du Sud.

Fonseca, C. (2008). Homoparentalidade: Novas luzes sobre o parentesco. Revista Estudos Feministas, 16(3), 769-783.

Futino, R. S., \& Martins, S. (2006). Adoção por homossexuais: Uma nova configuração familiar sob os olhares da Psicologia e do Direito. Aletheia, 24, 149-159.

Golombok, S., \& Tasker, F. (1996). Do parents influence the sexual orientation of their children? Findings from a longitudinal study of lesbian familiars. Developmental Psychology, 32(1), 3-11.

Grossi, M. P. (2003). Gênero e parentesco: Famílias gays e lésbicas no Brasil. Cadernos Pagu, 21, 261-280.
Heilborn, M. L. (1992). Dois é par: Conjugalidade, gênero e identidade em contexto igualitário (Tese de Doutorado não publicada). Universidade Federal do Rio de Janeiro, Rio de Janeiro.

Langouët, G. (1998). Les nouvelles familles en France: Observatoire de l'Enfance en France. Paris: Hachette.

Mattar, L. D. (2008). Reconhecimento jurídico dos direitos sexuais: Uma análise comparativa com os direitos reprodutivos. Revista Internacional de Direitos Humanos, 5(8), 60-83.

Medeiros, C. P. (2006). "Uma família de mulheres": Ensaio etnográfico sobre homoparentalidade na periferia de São Paulo. Revista Estudos Feministas, 14(2), 535-547.

Mello, L. (2005a). Outras famílias: A construção social da conjugalidade homossexual no Brasil. Cadernos Pagu, 24, 197-225.

Mello, L. (2005b). Novas famílias. Rio de Janeiro: Garamond.

Moris, V. L. (2008). Preciso te contar? Paternidade homoafetiva e a revelação para os filhos. (Tese de Doutorado). Recuperado de http:/www.sapientia. pucsp.br//tde_busca/arquivo.php?codArquivo $=8211$

Passos, M. C. (2005). Homoparentalidade: Uma entre outras formas de ser família. Psicologia Clínica, 17(2), 31-40.

Perelson, S. (2006). A parentalidade homossexual: Uma exposição do debate psicanalítico no cenário francês atual. Revista Estudos Feministas, 14(3), 709-730.

Rodriguez, B. C., \& Paiva, M. L. S. C. (2009). Um estudo sobre o exercício da parentalidade em contexto homoparental. Vinculo, 6(1), 13-25.

Ruas, A. P. F., Costa, C. G., Rodrigues, E. G., Pascon, J., Cristovão, M. A. M., Meirelles, M. C. M., ... Teixeira Filho, F. S. (2009). Adoção: Gênero, cidadania e direitos humanos. Revista de Psicologia da UNESP, 8(2), 1724. Recuperado de http://www2.assis.unesp.br/revpsico/index.php/revista/ article/view/130/154

Santos, C. (2004). A parentalidade em familias homossexuais com filhos: Um estudo fenomenológico de vivencias de gays e lésbicas. (Tese de Doutorado não publicada). Universidade de São Paulo, Ribeirão Preto.

Scorsolini-Comin, F., \& Cecílio, M. S. (2012). Pelo direito humano de amar: Apontamentos sobre a adoção por casais homossexuais no Brasil. In S. M. Barroso \& F. Scorsolini-Comin (Orgs.), Diálogos em Psicologia: Práticas profissionais e produção do conhecimento (pp. 47-60). Uberaba, MG: UFTM.

Silva, A. P. R., \& Tavares, M. T. (2007). Adoção por homossexuais no Brasil. Horizonte Científico, 1(1), 1-22.

Solis-Ponton, L. (2002). La parentalité: Défi pour le troisième millénaire. Paris: PUF.

Tarnovski, F. L. (2002). Pais assumidos: Adoção e paternidade homossexual no Brasil contemporâneo. (Dissertação de Mestrado não publicada). Universidade Federal de Santa Catarina, Florianópolis.

Tavares, F. H., Souza, I. A., Ferreira, I. E. V., \& Bomtempo, T. V. (2010). Apontamentos para o reconhecimento das uniões homossexuais face ao paradigma do estado democrático de direito. Revista Direito $G V, 6(2)$, 443-468.

Uziel, A. P. (2007). Homossexualidade e adoção. Rio de Janeiro: Garamond.

Vecho, O., \& Schneider, B. (2005). Homoparentalité et développement de l'enfant: Bilan de trente ans de publications. Psychiatrie de l'enfant, 48(1), 271-328.

Winnicott, D. W. (1993). A família e o desenvolvimento individual (3 $3^{\mathrm{a}}$ ed., M. B. Cipolla, Trad.). São Paulo: Martins Fontes.

Zambrano, E. (2006). Parentalidades “impensáveis”: Pais/mães homossexuais, travestis e transexuais. Horizontes Antropológicos, 12(26), 123-147. 
Mariana Silva Cecílio, é graduanda em Psicologia pela Universidade Federal do Triângulo Mineiro (UFTM). Endereço para correspondência: Departamento de Psicologia. Universidade Federal do Triângulo Mineiro (UFTM). Avenida Getúlio Guaritá, 159, Abadia, Uberaba, MG. CEP: 38025-440. Telefone: (34) 3318-5904. E-mail: mari_cecilio@hotmail.com

Fabio Scorsolini-Comin, doutor em Psicologia pela Universidade de São Paulo (USP), pós-doutorando em Psicologia pela Universidade de São Paulo (USP), é professor adjunto do departamento de Psicologia da Universidade Federal do Triângulo Mineiro (UFTM). E-mail: scorsolini_usp@yahoo.com.br

Manoel Antônio dos Santos, livre-docente em Psicoterapia Psicanalítica pela Universidade de São Paulo (USP), é professor associado 3 do departamento de Psicologia da Faculdade de Filosofia, Ciências e Letras de Ribeirão Preto da Universidade de São Paulo (FFCLRP-USP). E-mail: masantos@ffclrp.usp.br 